\title{
Ergenlerde Sanal Zorbalık, Beden İmgesi ve Duygusal Zekâ Arasındaki Yordayıcı İlişkiler
}

\author{
DOI: 10.26466/opus.761037 \\ * \\ Mehmet Nurullah Kırat* - Bülent Dilmaç ** \\ * Uzm. Psk. Dan., Atatürk Anadolu Lisesi, İstanbul/Türkiye \\ E-Posta: mnkirat34@gmail.com \\ ORCID: $\quad$ 0000-0003-3940-4507 \\ ** Prof. Dr., Necmettin Erbakan Üniversitesi,Ereğli Eğitim Fakültesi, Konya/Türkiye \\ E-Posta: bulentdilmac@gmail.com \\ ORCID: $\underline{0000-0001-5753-9355}$
}

\section{Öz}

$B u$ araştırma ergenlerde sanal zorbalık, beden imgesi ve duygusal zekâ arasındaki yordayıcı ilişkilerin incelenmesi amacıyla yapılmıştır. Araştırmanın çalışma grubunu basit tesadüfi küme örnekleme yöntemi ile tespit edilen 2018-2019 öğretim yılında İstanbul ilinde farkl liselerde öğrenim gören 213'ü kız, 308'i erkek öğrencilerden oluşan toplam 521 öğrenci oluşturmaktadır. Araştırmada veri toplama aracı olarak Siber Zorbalık Ölçeği, Duygusal Zekâ Ölçeği, Çok Boyutlu Bedenini Değerlendirme Ölçeği ve katılımcıların demografik özelliklerini belirlemek amacıyla kişisel bilgi formu kullanılmıştır. Araştırmada, ergenlerin sanal zorbalık, beden imgesi ve duygusal zekâları arasındaki ilişkilerin sınanması amacıyla yapısal eşitlik modeli analizi yapılmıştır. Araştırma sonucunda ise, ergenlerin duygusal zekâları ile beden memnuniyeti arasındaki yordayıcı ilişkiler incelendiğinde, pozitif yönlü doğrusal bir ilişki olduğu görülmüştür. Bir başka ifadeyle elde edilen bulgular, ergenlerin duygusal zekâsının artmasıyla ergenlerin beden memnuniyetinde de artış olacă̆ı saptanmıştır. Aynı zamanda ergenlerin duygusal zekâları ile sanal zorbalıkları arasındaki yordayıcı ilişkiler incelendiğinde, negatif yönlü doğrusal bir ilişki olduğu görülmüş̧ür. Diğer bir ifadeyle elde edilen bulgular, ergenlerin duygusal zekâları arttıkça sanal zorbalıklarında azalacağını ortaya çıkarmıştır.

Anahtar Kelimeler: Sanal Zorbalık, Duygusal Zekâ, Beden Imgesi, Ergenler. 
ISSN: 2528-9527

E-ISSN : 2528-9535

Yıl Year: 11

Cilt Volume: 17

Sayı Issue: 35

Mart March 2021

Makalenin Geliș Tarihi Received Date. 30/06/2020

Makalenin Kabul Tarihi Accepted Date. 19/02/2021

\title{
Predictive Relationships Between Cyber Bulliying, Body Image And Emotional İntelligence In Adolescents
}

\begin{abstract}
This research is for examining the predictive relationship between virtual bullying, body image and emotional intelligence in adolescents. The study group of the study consists of 521 students, 213 of whom are female and 308 of whom are male, studying in different high schools in Istanbul, which is determined by simple random set sampling method. In the research, Cyber Bullying Scale, Emotional Intelligence Scale, Multidimensional Body Evaluation Scale and personal information form were used to determine the demographic characteristics of the participants. In the study, structural equality model analysis was carried out to test the relationships between adolescents' virtual bullying, body image and emotional intelligence. As a result of the study, when the predictive relationships between emotional intelligence and body satisfaction of adolescents were examined, it was observed that there was a positive linear relationship. In other words, the findings have been found to increase the body satisfaction of adolescents with the increase of emotional intelligence of adolescents. At the same time, when the predictive relationships between emotional intelligence and adolescent bullying of adolescents were examined, it was observed that there was a negative linear relationship. In other words, the findings revealed that adolescents will decrease in their cyber bullying as their emotional intelligence increases.
\end{abstract}

Keywords: Virtual Bullying, Emotional intelligence, Body Image, Adolescents. 


\section{Giriş}

Karmaşık bir canlı türü olan insanın davranışlarını belirleyen pek çok faktör vardır. Ancak bu faktörlerin başında insanın ihtiyaçları ve güdüleri gelmektedir (Arıcak, 2015). İhtiyaçlar boyutuyla düşünüldüğünde özellikle ergenler bu dönemde içe kapanmaya meyilli ve özgüvensiz oldukları için sanal ortamlar onlara, kendilerini tanıma ve uygun davranış biçimlerini deneyerek öğrenme fırsatı sağlamaktadır. Farklı kültürleri tanıma imkânı bulabilirler. Dünyanın farklı bölgelerinde yaşayan ve benzer hobileri, ilgi alanları olan bireylerin birbirleriyle ilişki kurmalarını sağlayan internet ortamı bireyin çevresinin genişlemesine yardımcı olur (Ögel, 2012). Fakat sadece bu olumlu yanları ile sınırlı kalmaz. İnsanoğlu belirli temel ihtiyaçları dışında bazı güdülere de sahiptir. Bunlar ise; saldırganlık ve cinselliktir. Özellikle saldırganlık ve cinsellik internet teknolojisinde kendine karşılık bulabilmiş iki önemli güdüdür (Arıcak, 2015). Bu ergenlik döneminde ergenler bu saldırganlık güdüsünü sanal ortamlara taşıyarak, çevresindekilere zarar verme, tehdit etme boyutuna taşımaktadırlar. Bu zorbalığın internet ortamına taşınması haline de sanal zorbalık denilmiştir. Sanal zorbalık, bilgi ve iletişim teknolojileri aracllğı̆la bireylerin veya grupların çevresindeki bireylere veya gruplara zarar vermeyi amaçlayarak kasıtll, tasarlanmış zorbalık türüdür (Campell, 2005). Sanal zorbalık Willard (2007)'a göre, bireyin elektronik ortamda diğer bireyleri rahatsız etmek için mesaj göndermesi veya sosyal saldırganlık yapmasıdır. Li (2006) ise sanal zorbalığı, cep telefonu, e-posta, mesajlaşma, web sitelerinde etraftaki kişileri karalama gibi amaçlarla bireyin çevresine kasıtlı olarak düşmanca tavırlar sergilemesi olarak tanımlamıştır. Arıcak (2011) siber zorbalık kavramını, "bilgi ve iletişim teknolojilerini aracılığıyla birey veya kişilere, özel veya tüzel kişiliklerine karşılık yapılan tekniksel veya ilişkisel tarzda zarar verme davranışlarının tümünü kapsar" şeklinde tanımlamıştır.

Olweus (1993)'a göre zorbalık; aralarında belirgin düzeyde güç farkı olan kişilerden güçlü olanın savunmasız olana karşı kasıtlı bir şekilde ve tekrarlayarak saldırganca eylemlerde bulunması olarak tanımlanmaktadır. Aynı zamanda davranışın zorbalık şeklinde tanımlanması için üç gerekli koşulu sağlaması gerekmektedir. Bunlar; kasıtlı olarak karşısındakine zarar verme amacıyla saldırganca davranma, yapılan bu davranışların sürekli olarak tekrarlanması ve iki taraf arasında belirgin düzeyde güç farklarının bulunmasıdır (Olweus, 1999; akt. Kavuk, 2011). Sanal zorbalık, teknolojinin kullanılmasıyla 
bağlantılı olduğundan teknolojinin ilerleyen zamanlarda daha ulaşılabilir hale gelmesi ve gelişmesi yaşanan olayların artacağını göstermektedir. Bu sebeple okullarda öğrencilere bu imkanların ve araçların ne amaçla ve nasıl kullanılması gerektiği ile ilgili eğitimler verilmeli, bu araçların yanlış kullanılması sonucunda kişilerin yaşadığı olumsuzlukları aktaran bilgilendirmeler yapilmalidır (Ayas ve Horzum, 2011).

Ergenlik dönemi aslında ergenlerin beden yapılarının sürekli değişime uğradığı, ergenlerin duygusal olarak karmaşıklaştığı bir dönemdir. Bu karmaşıklıkla birlikte ergenlerde dış görünüş kaygıları ortaya çıkabilmektedir. Olumsuz bir beden algisı ve beraberinde gelen olumsuz bir benlik saygisı ile ergen tamamen bir yıkım süreci içerisinde olduğunu hissedebilir. Bu dönemde bedenindeki en ufak kusurlar dahi tahammül edilemez bir şekilde reddedilmekte ve problem durumu haline gelmektedir. Bu dönemde olumlu bir beden imgesi oluşturmak da önemli bir konu olmaktadır. Eğer bu olumlu beden algısı oluşturulamazsa bu durum zamanla bireyin sosyalleşmesini ve kişilik yapısında bazı sorunları da beraberinde getirecektir. Beden imgesi, bireylerin kendilerini algilayış biçimleriyle ve değerlendirmesiyle oluşan görüşleridir (Kulaksızoğlu, 2000). Diğer bir tanıma göre ise beden imgesi, insanın kendini algılama şekli, kim ve ne olduğu hakkındaki görüşleri yani kimliğine dair düşüncelerini kapsar (Yavuzer, 2002). Yörükoğlu (1990) ise beden imgesi kavramın, bireyin kendini nasıl gördüğü ve buna bağlı olarak kendine verdiği değer olarak tanımlamıştır. Muth ve Cash (1997)'e göre beden imgesi, bireylerin fizyolojik yapılarına ilişkin hissettikleri duygu, düşünce ve davranışların kavramsallaşmış halidir. Dış görünüş, bireylerin hem kendilerini değerlendirmeleri hem de sosyal anlamda da güçlü bir uyaran olmasından ötürü beden imgesinde belirleyicilik taşımaktadır. Beden imgesi bu anlamda incelendiğinde fiziksel benliğin görüntüsü olarak tanımlanmaktadır (Koç, 2004). Beden algısının ilk belirleyicileri anne babalar ve ailedir. İkinci olarak arkadaş çevresi, üçüncü sırada ise okul bulunmaktadır. Bireyler disiplin ve sevgi yoluyla anne babadan, uyumlu davranışlar gösterme çabası ile akranlarından, başarılı olma veya olamama durumu ile de okuldan etkilenmektedir. Bu üç aşamada da bireyin yaşantıları olumlu devam ederse pozitif ve kapsayıcı bir beden algısı oluşur (Gander ve Gardiner, 1995). Cinsiyet, yaş, etnik köken, çok kültürlülük ve mükemmeliyetçilik gibi faktörler beden imgesini biçimlendirmekte ve gelişiminde büyük oranda rol oynamaktadır (Smolak, 2004). 
Günümüzde bireyler hızlı ve yoğun bir değişim yaşamaktadırlar. Bu değişimler bireylere farklı roller ve statüler yüklemiştir. Kişinin bu rolleri ve statüleri oluşturabilmesi yalnızca klasik zekâ (IQ) potansiyeli değil son yıllarda da üzerinde çokça çalışmanın yapıldığı duygusal zekâ ile mümkündür. Duygu insanların iç ve dış dünyadan etkilenmesi ve bu etki sonucunda genel olarak "hoşlanma" veya "acı duyma" şeklinde ortaya çıkan tepkilerin tümüdür. İnsanların temel ihtiyaçlarıyla ve onun bir sonucu olarak ortaya çıkan davranışlarıyla ilişkilidir. Bu sebeple insan davranışlarına hakim olmak, duyguları inceleyip anlamak ile mümkündür. Duygunun birden oluşanı ve şiddetli olanına coşku denirken; öfke, korku, sevinç ve üzüntü coşkunun diğer türüdür. Her ikisi de aynı kaynaktan beslenmektedir (Binbaşığlu, 1990). Zekâ kavramı ise bilgiyi öğrenme ve kaydetme, ilişkilendirerek yorumlama, akıl tutup kaydetme, akıl yürütme, algılama, sezebilme ve çağrışım yapma gibi özellikleri olan beyne ait bir kapasitedir. Cevap vermede ve çözüm bulmada hız sağlayan, problemlerin evreleri arasında ilişki kurmaya yarayan kapasitedir. Kişilerin öğrendiklerin bilgilerin türü, hızı, miktarı, akılda tutma süreci arasındaki değişiklikler onların zekâ düzeylerini ve biçimlerini ortaya koyar (Yerli, 2009). Bu tanımlamalardan yola çıarak incelediğimizde duygusal zekâ İngilizce 'de "emotional intelligence" sözcüklerinin kısa hali yani EI olarak bilinmektedir. Literatürde ise yaygın olarak kullanılışı EQ (Emotional Quotient)dur (Sudak, 2011; akt. Aydın, 2017, s.5). Duygusal zeka, duygular1 doğru anlayıp iyi ifade edebilme, duyguları bilişsel süreçlerle entegre edebilme, duyguları anlama ve olay ve durumlar üzerinde duyguların etkilerini anlayabilmek gibi duygusal becerileri içinde barındırmaktadır( Law, Song ve Wong, 2000 akt. Gürbüz ve Yüksel, 2008: 174). Duygusal zeka bu zeka türünün beş önemli unsuru olan öz bilinç, motivasyon, kendine çeki düzen verme, empati ve ilişkilerde ustalık gibi temel nitelikteki becerileri öğrenebilme potansiyelimizi ortaya çıkarır. Duygusal yeterliliğimiz ise iş başındaki becerilerimize bu potansiyeli nasıl aktarabileceğimizi gösterir (Goleman, 2000).

$\mathrm{Bu}$ alanlarda yapılan araştırmalar incelendiğinde duygusal zekayla ilgili ülkemizde ilk çalışmaların 2000'li yıllarda yapıldığı görülmüş̧ür. Fakat yurt dışında yapılan araştırmalara baktığımızda daha önceki yıllarda duygusal zekanın klasik zekaya göre daha değerli görüldüğü ve bu konuda araştırmaların yapıldığına rastlanmıştır. Özellikle son dönemlerde oldukça merak edi- 
len ve çalışılan diğer bir konu ise sanal zorbalıktır. Teknolojik gelişim ve değişimle birlikte yaşanan zorbalık türlerinin sanal ortamlarda yaşanması bu konuda uzmanların araştırmalar yapmasını sağlamıştır. Yurt dışında 1990'lı yıllarda başlayan bu çalışmalar ülkemizde teknolojik aletlerin artmasıyla birlikte son yıllarda oldukça artmakta ve alınacak önlemlere yönelik çalışmalar yapılmaktadır. Son olarak beden imgesi kavramına yönelik yapılmış araştırmalar incelendiğinde 1990'lı yıllardan bu yana çok fazla araştırma yapıldığ gözlemlenmiştir. Fakat bu yapılan araştırmaların ergenlerdeki sanal zorbalık ve duygusal zekâ ile ilişkileri gerektiği kadarıyla incelenmediğinden bu konuda önemli bir eksik olduğu görülmektedir. Bu çalışmanın bu alandaki bu önemli eksiği dolduracağı varsayılmaktadır. Dolayısıyla bu önem doğrultusunda araştırmanın amacı ergenlerde sanal zorbalık, beden imgesi ve duygusal zekâ arasındaki ilişsileri incelemektedir.

\section{Yöntem}

Bu bölümde araştırma modeli, çalışma grubu, veri toplama araçları, verilerin toplanması ve verilerin nasıl analiz edildiği konusunda bilgilere yer verilmiştir.

\section{Araştırma Modeli}

Nicel araştırma paradşgmasına sahip bu çalışmada, ergenlerde sanal zorbalık, beden imgesi ve duygusal zeka arasındaki ilişkilerin belirlenmesi ve bu değişkenler aralarındaki ilişkilerin yapısal eşitlik modeli ile sınanması amaçlanmıştır. Bu amaç doğrultusunda araştırma, genel tarama modelinin bir alt türü olan ilişkisel tarama modeline göre gerçekleştirilmiştir. Genel tarama modelleri, çok sayıda elemandan oluşan bir evrende, evrenin tamamı ya da evrenden alınacak bir grup örnek ya da örneklem üzerinde, evren hakkında genel bir yargıya ulaşmak amacıyla yapılan tarama araştırmalarıdır. Genel tarama modelleri ilişkisel ve ya tekil taramalar yapmaya imkân verir. İlişkisel tarama modelleri, iki ya da daha fazla sayıdaki değişken arasındaki değişimin birlikte var olup olmadığını veya bu değişimin derecesini belirlemeyi amaçlayan araştırma modelleridir (Karasar, 2015). 


\section{Çalışma Grubu}

Araştırmanın çalışma grubunu basit tesadüfi küme örnekleme yöntemi ile tespit edilen İstanbul ilinde farklı liselerde öğrenim gören 213' ü kız, 308'i erkek öğrencilerden oluşan toplam 521 öğrenciden oluşmaktadır.

\section{Veri Toplamada Kullanılan Ölçme Araçları}

Bu araştırmada veri toplama aracı olarak Siber Zorbalık Ölçeği ve Çok Boyutlu Bedenini Değerlendirme Ölçeği, Duygusal Zeka Ölçeği ve katılımcıların demografik özelliklerini belirlemek amacıyla kişisel bilgi formu kullanılmiştır.

Kişisel Bilgi Formu: Katılımcların yaş, cinsiyet, anne ve baba eğitim durumu, kardeş sayısı ve kaçıncı kardeş olduğu hakkındaki bilgileri toplamak amacıyla araştırmacı tarafından hazırlanan kişisel bilgi formu kullanılmıştır.

Çok Boyutlu Bedenini Değerlendirme Ölçeği: Çok Boyutlu Bedenini Değerlendirme Ölçeği (The Multidimensional Body-Self Relations Questionnaire; (MBSRQ), Cash, (2000) özellikle dış görünüş ve beden imgesi ile ilgili kognitif ve duygusal etkenleri değerlendirmektedir. Ölçek, dış görünüşü değerlendirmesi $\left(3,5,9,12,15,18^{*}, 19^{*}\right)$, dış görünüş oryantasyonu $\left(1,2,6,7,10,11^{*}, 13,14^{*}, 16^{*}\right.$, $\left.17,20^{*}, 21\right)$, aşırı kilo ile meşgul olma $(4,8,22,23)$, kilo ile ilgili kendini sınıflandırma $(24,25)$ ve beden bölgeleri memnuniyeti $(26,27,28,29,30,31,32,33,34)$ olmak üzere beş alt faktöre sahiptir. Bu çalışmada tek bir beden imgesi skoru kullanılmıştır. İlk 22 soru için kişinin tepkileri "kesinlikle katılmıyorum" ve "kesinlikle katılıyorum", 23. Soru "hiçbir zaman" ve "çok sık", 24-25. sorular için "çok zayıf" veya "çok kiloluyum", 26 ve 34. arasındaki sorular için "çok memnunum" ve "çok memnuniyetsizim" arasında değişen 5'li Likert tip ölçek üzerinden olmaktadır. Puanlar arttı̆g 1 durumlarda beden memnuniyeti de artmaktadır. Ölçekteki ters maddeler ise 11, 14, 16, 18, 19, $20^{\prime}$ dir.

Kullanılan çok boyutlu bedenini değerlendirme ölçeğinin geçerlilik ve güvenirlilik çalışması daha önce yapılmadığı için bu çalışma kapsamında yapılmıştır. Yapmış olduğumuz çalışma sonucunda ise şu bulgulara ulaşılmıştır. 


\begin{tabular}{ll}
\hline & CronbachAlfa \\
\hline Dış görünüşü değerlendirmesi & .832 \\
\hline Dış görünüş oryantasyonu & .754 \\
\hline Aşırı kilo ile meşgul olma & .659 \\
\hline Kilo ile ilgili kendini sınıflandırma & .896 \\
\hline Beden bölgeleri memnuniyeti & .818 \\
\hline Ölçeğin geneli & .855 \\
\hline
\end{tabular}

Ölçek maddelerinin faktör yükleri .41 ile .91 arasında değişmektedir.

\section{Siber Zorbalık Ölçeği: (Not=Bu ölçeğin geçerlik ve güvenirlik rakamlarnı} eklendi): Arıcak, Kınay ve Tanrıkulu (2012), tarafından geliştirilen ölçeğin yapı geçerliliği, açımlayıcı faktör analizi ile incelenmiştir. Analiz sonucunda ölçeğin tek faktörlü bir yapı sergilediği görülmüştür. Bulunan bu tek faktör toplam varyansın \% 50,58' ini açıklamaktadır. Ölçeğin Cronbach alfa katsayısı 0,95 olarak; test-tekrar güvenirlik katsayısı 0,70 olarak bulunmuştur. Bu değerlere göre ölçeğin güvenilir olduğu söylenebilir. Ölçek 24 maddeden oluşan ve 4'lü Likert türünde (Hiçbir Zaman, Bazen, Çoğu Zaman, Her Zaman) puanlanan bir ölçektir. Ölçekten alınabilecek en düşük puan 24 en yüksek puan 96'dır. Ölçekten alınan puanların yüksek olması siber zorbalık davranışının fazlalığına işaret etmektedir.

\section{Duygusal Zekâ Ölçeği: (Not=Bu ölçeğin geçerlik ve güvenirlik rakamların} eklendi): Duygusal Zekâ Ölçeği, Petrides ve Furnham'ın (2000) duygusal zekâyı, kişisel bir karakter özelliği olarak kavramlaştırması esas alınarak geliştirilmiştir. Ölçeğin amacı, bireyin duygusal yeterlilikleriyle ilgili kendini algılama seviyesini belirlemektir. Ölçek, Petrides ve Furnham tarafından geliştirilen Trait Emotional Intelligence Questionnaire' in uzun formu temel alınarak hazırlanmıştır Ölçek, Öznel İyi Oluş, Duygusallık, Öz Kontrol ve Sosyallik olarak isimlendirilen dört alt ölçekten oluşmaktadır. Ölçeğin ölçüt bağıntılı geçerliği, DZÖÖ kısa formu toplam puanı ve iyi oluş, duygusallık, öz kontrol ve sosyallik alt boyutları için nevrotik kişilik özelliği ile negatif yönde anlamlı korelasyonlar ve deneyime açıklık, dışadönüklük, sorumluluk ve yumuşak başlılık alt boyutları ile pozitif yönde anlamlı korelasyonlarla desteklenmiştir (Petrides ve ark., 2010; akt. Deniz ve ark, 2013). Ölçeğin Türkçe geçerlik ve güvenirlik çalışması Deniz, Özer ve Işık (2013) tarafından gerçekleştirilmiştir. 464 üniversite öğrencisi üzerinde yürütülen çalışmada yapılan açıklayıcı faktör analizi sonucunda, 20 maddeden oluşan dört faktörlü bir 
yapı elde edilmiştir. DZÖÖ-KF"enun iç tutarlılık güvenirlik katsayısı ölçeğin tamamı için 0,81, test-tekrar test güvenirlik katsayısı ise 0,86 olarak bulunmuştur. Çalışmada kullanılan duygusal zekâ ölçeğinde verilen önermeler ile alakalı fikirlerini pozitif düşünceden negatif düşünceye doğru sıralanan seçeneklerden birini işaretleyerek belirtmeleri istenilmiştir. (Deniz, Özer ve Işık, 2013: 411).

\section{Verilerin Toplanması}

Verilerin Analizi: Araştırmada, ergenlerin sanal zorbalık, beden imgesi ve duygusal zekâları arasındaki ilişkilerin yapısal eşitlik modeli ile sınanması amacıyla yapısal eşitlik modeli analizi yapılmıştır. Yapısal eşitlik modeli kuramsal bir modeli analiz etmek için gözlemlenen ve gizil değişkenler arasındaki karşılıklı ve nedensel ilişkileri ortaya çıkaran istatistiksel bir modeldir (Shumacker ve Lomax, 2004). Yapısal eşitlik modellemesi analizi AMOS 19 Programı ile yapılmıştır.

Aynı zamanda toplanan verilerin yüzde ve frekans hesaplamaları SPSS 18 programı ile gerçekleştirilmiştir.

\section{Bulgular}

Elde edilen son modelde $\left(\mathrm{x}^{2} / \mathrm{sd}=108.632 / 30, \mathrm{p}<.001\right)$ dört gözlenen dışsal değişken, duygusal zeka (iyi oluş, öz kontrollük, sosyallik ve duygusallık) altı gözlenen içsel değişken (sanal zorbalık, dış görünüş değerlendirme, dış görünüş oryantasyonu, kilo ile meşguliyet, beden memnuniyeti ve kilo ile ilgili kendini sınıflandırma) değişken bulunmaktadır. Modelde görülen tüm yolların istatistiksel olarak anlamlı olduğu tespit edilmiştir. Normlaştırılmış Uyum İndeksi (NFI), Normlaştırılmamış Uyum İndeksi (TLI) ve diğer uyum indeksleri modelin iyi uyumlu olduğunu göstermektedir (Tablo-1). Modelde bulunan gözlenen içsel değişken verileri arasında iki yönlü korelasyonların her biri yüksek değerlere sahiptir ve istatistiksel olarak anlamlı olduğu görülmektedir. 
Tablo 1. Yaptsal Eşitlik Modelinin Uyumuna İlişkin İstatistiksel Değerler

\begin{tabular}{llll}
\hline Ölçüm & İyi Uyum & Kabul Edilebilir Uyum & Modelin Uyum İndeksi Değerleri \\
\hline$\left(X^{2} / \mathrm{sd}\right)$ & $\leq 3$ & $\leq 4-5$ & 3.62 \\
\hline RMSEA & $\leq 0.05$ & $0.06-0.08$ & 0.07 \\
\hline SRMR & $\leq 0.05$ & $0.06-0.08$ & 0.05 \\
\hline AGFI & $\geq 0.95$ & $0.94-0.90$ & 0.92 \\
\hline CFI & $\geq 0.95$ & $0.94-0.90$ & 0.90 \\
\hline IFI & $\geq 0.95$ & $0.94-0.90$ & 0.90 \\
\hline GFI & $\geq 0.90$ & $0.89-0.85$ & 0.96 \\
\hline
\end{tabular}

Tablo 1'de bulunan uyum değerleri incelendiğinde, $x^{2} / s d=3.62$, RMSEA $=0.07, \mathrm{SRMR}=0.05, \mathrm{CFI}=0.90, \mathrm{GFI}=0.96, \mathrm{AGFI}=0.92$ ve $\mathrm{IFI}=0.90$, olarak bulunmuştur. Genel olarak bakıldığında, modelin iyi uyum değerlerine sahip olduğu görülmektedir (Bollen, 1989; Browne ve Cudeck, 1993; Byrne, 2010; Hu ve Bentler, 1999; Kline, 2011; Tanaka ve Huba, 1985). Test edilen tek faktörlü model Şekil 1'de gösterilmektedir. Modelde gösterilen bütün yolların 0.001 düzeyinde anlamlı olduğu görülmektedir.

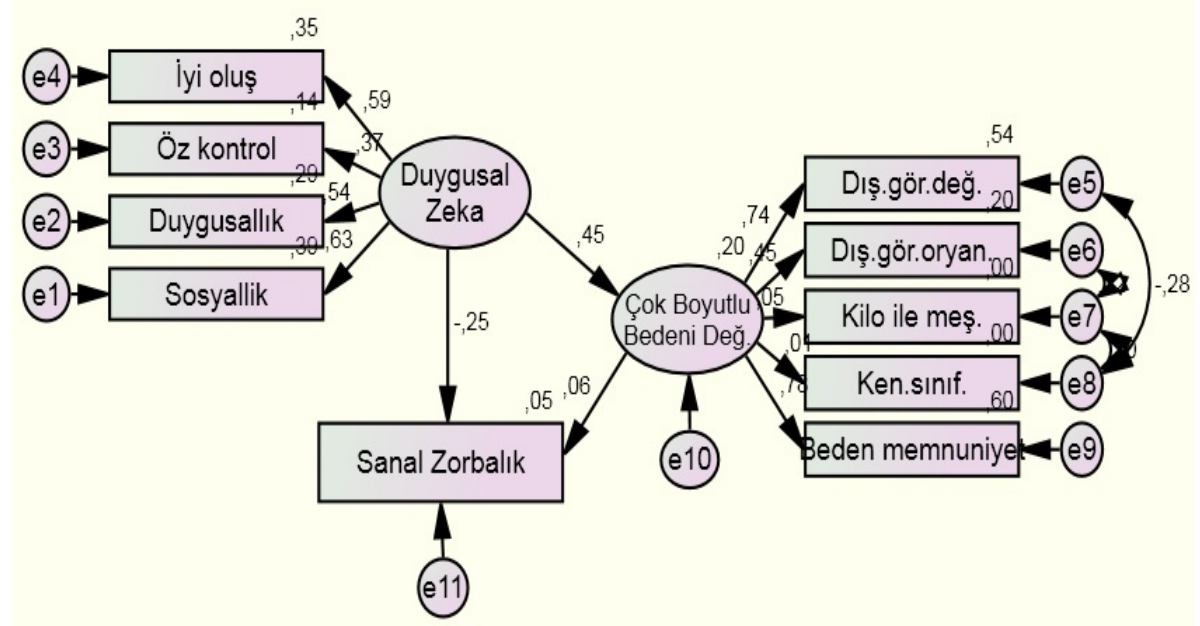

Şekil 1. Modele İlişkin Yol Analizi 
Tablo 2: Ergenlerde Sanal Zorbalık, Beden İmgesi Ve Duygusal Zekâ Arasındaki Yordayıcı Ilişkilere Yönelik Model

\begin{tabular}{lllllll}
\hline $\begin{array}{l}\text { Yordayıcı } \\
\text { Değişken }\end{array}$ & Bağımlı Değişken & $\begin{array}{l}\text { Toplam } \\
\text { Etki }\end{array}$ & $\begin{array}{l}\text { Doğrudan } \\
\text { Etki }\end{array}$ & $\begin{array}{l}\text { Dolaylı } \\
\text { Etki }\end{array}$ & $\begin{array}{l}\text { Standart } \\
\text { Hata }\end{array}$ & $\begin{array}{l}\text { Kritik } \\
\text { Değer }\end{array}$ \\
\hline Duygusal Zekâ & Beden Memnuniyeti & 0.45 & 0.45 & 0 & 0.12 & $5.95^{*}$ \\
\hline Duygusal Zekâ & Sanal Zorbalık & -0.25 & -0.25 & 0 & 0.26 & $-3.49^{*}$ \\
\hline $\begin{array}{l}\text { Beden } \\
\text { Memnuniyeti }\end{array}$ & Sanal Zorbalık & Anlamsız & & 0.91 \\
\hline
\end{tabular}

a Toplam etki $=$ Doğrudan etki + Dolaylı etki, ${ }^{*} \mathrm{p}<0.01,{ }^{* *} \mathrm{p}<0.05$.

Tablo incelendiğinde, beden memnuniyeti etkileyen önemli bağımsız değişken $(t=5.95, p<0.01)$ duygusal zekâ değişkeni olduğu görülmektedir. Bu faktöre ait bağlantı katsayı değeri $\beta=0.45$ olarak bulunmuştur. Ergenlerin duygusal zekâları ile beden memnuniyeti arasındaki yordayıc ilişkiler incelendiğinde, pozitif yönde anlamlı bir ilişkinin olduğu görülmektedir. Bir başka ifadeyle elde edilen bulgular, ergenlerin duygusal zekâsının artmasıyla ergenlerin beden memnuniyetinde de artış olacağını göstermektedir.

Modelde sanal zorbalığı etkileyen önemli diğer değişkenin $(t=-3.49$, $p<0.01)$ duygusal zekâ olduğu görülmektedir. Bu faktöre dair bağlantı katsayı değeri $\beta=-0.25$ olarak ortaya konmuştur. Ergenlerin duygusal zekâları ve sanal zorbalıkları arasındaki yordayıcı ilişkiler incelendiğinde, negatif yönde doğrusal ve anlamlı bir ilişki olduğu görülmektedir. Diğer bir ifadeyle elde edilen bulgular, ergenlerin duygusal zekâları arttıkça sanal zorbalıklarında azalacağını ortaya koymaktadır.

\section{Tartışma ve Yorum}

Çalışmanın araştırma grubunu oluşturan ergenlerde sanal zorbalık, beden imgesi ve duygusal zekâ arasındaki ilişkinin incelenmesi sonucunda elde edilen bulguların bu bölümde de tartışması yapılmış ve yorumlanmıştır.

Araştırmada ergenlerin beden memnuniyetleri ile (dış görünüşü değerlendirmesi, dış görünüş oryantasyonu, aşırı kilo ile meşgul olma, kilo ile ilgili kendini sınıflandırma, beden bölgeleri memnuniyeti) duygusal zekâ alt ölçeklerinden olan iyi oluş, öz kontrol, duygusallık ve sosyallik arasında pozitif yönde anlamlı ve doğrusal bir ilişki olduğu tespit edilmiştir. Diğer bir ifa- 
deyle ergenlerin duygusal zekâları arttıkça bedenlerinden memnun olma düzeyleri de artmaktadır. Duygusal zeka, duyguları doğru anlayıp ifade edebilme, duyguları bilişsel süreçlerle entegre edebilme, duyguları anlama ve duyguların olay ve durumlar üzerindeki etkilerini anlayabilme gibi duygusal yetenekleri içinde barındırmaktadır( Law, Wong, Song, 2000 akt, Gürbüz ve Yüksel, 2008, s.174).

Yapılan diğer araştırmalara bakıldığında, Costarelli ve Stamou (2009) yaptıkları çalışmada duygusal zekâ ve beden imajı arasında pozitif bir ilişki olduğu ve sporcuların sporcu olmayanlara göre yüksek düzeyde duygusal zekâya ve daha sağlıklı bir beden algısına sahip olduklarını tespit etmişlerdir. Diğer bir araştırmada ise Swami, Begum ve Petrides (2010),duygusal zekâ ile bedensel takdir arasındaki ilişkiyi incelemişler ve duygusal zeka ile beden takdiri arasında pozitif yönde anlamlı bir ilişkinin olduğunu tespit etmişlerdir.

Beden imgesi bireyin kendi kişiliğine, sahip olduğu değerlere ve çevresindekilerle olan ilişkilerine bağlı olarak oluşan kişisel düşünceleri ile şekillenir (Şanlı, 1991). Yurt içinde bu değişkenlere ilişkin araştırmalar yapılmış olsa da birbiri arasındaki ilişkiyi inceleyen çalışmalar bulunmamaktadır. Bundan dolayı duygusal zekânın alt maddelerinden olan iyi oluş, sosyallik vb. kavramlar ve beden imgesi ile ilişkili olduğu düşünülen beden algısı, beden memnuniyeti vb. kavramlar ile ilişkili araştırmalar incelenmiştir. Çelik (2008), yaptığı araştırmada iyi oluş ile duygusal zekâ arasında pozitif yönlü anlamlı bir ilişki olduğunu tespit etmiştir. Yine başka bir araştırmada ise duygusal zekâ ile sosyal beceri arasında pozitif yönlü anlamlı bir ilişkinin olduğu görülmüştür (Yurdakavuştu, 2012). Buradan yola çıkarak yapılan bu araştırmanın literatürde yapılmış birçok araştırmayla uyumlu olduğu görülmektedir.

Araştırmadan elde edilen diğer bir bulgu ise, ergenlerin sahip oldukları duygusal zekâları ile sanal zorbalıkları arasındaki ilişkinin incelenmesi sonucunda, duygusal zekâ ile sanal zorbalık arasında negatif yönlü anlamlı bir ilişki tespit edilmiştir. Diğer bir ifadeyle, ergenlerin duygusal zekâları arttıkça sanal zorbalıkları azalmaktadır. Sanal zorbalık, bilgi ve iletişim teknolojileri aracılığıyla bireylerin veya grupların çevresindeki bireylere veya gruplara zarar vermeyi amaçlayarak kasıtlı, tasarlanmış zorbalık türüdür (Campell, 2005). Buradan yola çıkarak bu değişkenlere ilişkin yapılan diğer araştırmalar incelendiğinde, Baroncelli ve Ciucci (2014)'nin duygusal zekâ ile geleneksel/siber zorbalık arasındaki ilişkiyi incelediği araştırmada duygusal zekânın 
duyguların düzenlenmesi ve kullanılmasıyla ilgili alt boyutunun hem geleneksel zorbalığı hem de sanal zorbalığı negatif yönde anlamlı bir biçimde yordadığı ortaya çıkmıştır. Bir başka araştırmada yine, duygusal zekâ ile siber zorbalık arasında negatif yönde anlamlı bir ilişki olduğu saptanmıştır (Ojedokun ve Idemudia, 2013). Extremera, Quintana-Orts, Merida-Lopez ve Rey'in 2018 yılında yaptıkları çalışmada duygusal zekâ ile siber suçları arasında negatif yönlü bir ilişki olduğu tespit edilmiştir. Buradan yola çıkarak, yapılan bu araştırmanın daha önceden yapılan araştırmaların bir devamı niteliğinde olduğu ve uyumluluk gösterdiğini görülmektedir. Bu çalışma 14 ile 19 yaşlar arası ergenler ile sınırlı tutulmuştur. Yapılan bu araştırmada İstanbul ilinde lise düzeyinde öğrenim gören ergenler ile çalışılmıştır. Gelecekte yapılacak çalışmalar, farklı eğitim kademelerinde yürütülebileceği gibi, üniversite düzeyini de kapsayacak şekilde genişletilebilir. Çalışmanın genellenebilmesine katkısı olacağı düşünülerek bu çalışmanın diğer illerde öğrenim gören ergenlere de uygulanmasının büyük bir açığı kapatacağı düşünülmektedir. 


\title{
EXTENDED ABSTRACT
}

\section{Predictive Relationships Between Cyber Bulliying, Body Image And Emotional İntelligence In Adolescents}

\author{
Mehmet Nurullah Kırat - Bülent Dilmaç \\ Ministry of National Education, Necmettin Erbakan University
}

This study was conducted to examine the predictive relationships between cyberbullying, body image and emotional intelligence in adolescents. The study group of the research consists of a total of 521 students, 213 female and 308 male students studying at different high schools in Istanbul in the 20182019 academic year, which was determined by simple random cluster sampling method. Cyber Bullying Scale, Emotional Intelligence Scale, Multidimensional Body Assessment Scale and personal information form were used to determine the demographic characteristics of the participants in the study. In the study, structural equation model analysis was conducted to test the relationships between cyberbullying, body image and emotional intelligence of adolescents.

Adolescence is actually a period in which the body structures of adolescents are constantly changing and adolescents become emotionally complex. With this complexity, appearance concerns may arise in adolescents. With a negative body perception and the accompanying negative self-esteem, the adolescent can feel that he is in a completely destructive process. During this period, even the smallest defects in his body are intolerably rejected and become a problem situation. Creating a positive body image is also an important issue in this period. If this positive body perception cannot be created, this will bring along some problems in the individual's socialization and personality structure over time. Body image is the opinions formed by individuals' perception and evaluation of themselves (Kulaksızoğlu, 2000). According to another definition, body image includes the way people perceive themselves, their opinions about who and what they are, that is, their thoughts about their identity (Yavuzer, 2002). Yörükoğlu (1990) defined the concept of body image as how the individual sees himself and the value he gives to himself 
accordingly. According to Muth and Cash (1997), body image is the conceptualized state of feelings, thoughts and behaviors felt by individuals regarding their physiological structures. External appearance is decisive in the body image because individuals evaluate themselves and are a powerful stimulus in social terms. When body image is examined in this sense, it is defined as the image of the physical self (Koç, 2004). The first determinants of body perception are parents and family. The second is the circle of friends and the third is the school. Individuals are influenced by their parents through discipline and love, by their peers with the effort to demonstrate harmonious behavior, and from the school with their success or failure. In all three stages, if the life of the individual continues positively, a positive and inclusive body perception occurs (Gander and Gardiner, 1995). Factors such as gender, age, ethnicity, multiculturalism and perfectionism shape the body image and play a major role in its development (Smolak, 2004).

Today, individuals are experiencing rapid and intense change. These changes have imposed different roles and status on individuals. The ability of a person to create these roles and statuses is possible not only with the classical intelligence (IQ) potential, but also with emotional intelligence, which has been studied a lot in recent years. Emotion is all of the reactions that people are affected by the inner and outer world and as a result of this effect, generally "like" or "pain". It is related to the basic needs of people and the behaviors that occur as a result of it. For this reason, it is possible to master human behavior by examining and understanding emotions. While the sudden and severe emotion is called enthusiasm; Anger, fear, joy, and sadness are other types of euphoria. Both are fed from the same source (Binbaşığlu, 1990). The concept of intelligence, on the other hand, is a capacity belonging to the brain, which has features such as learning and recording information, interpreting by associating, keeping reasoning, reasoning, perception, sensing and association. It is the capacity that provides speed in responding and finding solutions, and establishing relationships between the stages of problems. Changes between the type, speed, amount of information that people have learned, and the process of keeping in mind reveal their intelligence levels and forms (Yerli, 2009). When examined based on these definitions, emotional intelligence is known as EI, which is the short form of the words "emotional intelligence" in English. In the literature, it is commonly used as EQ 
(Emotional Quotient) (Sudak, 2011; cited in Aydın, 2017, p.5). Emotional intelligence includes emotional skills such as understanding and expressing emotions correctly, integrating emotions with cognitive processes, understanding emotions, and understanding the effects of emotions on events and situations (Law, Song and Wong, 2000 cited in Gürbüz and Yüksel, 2008: 174). Emotional intelligence reveals our potential to learn basic skills such as selfconsciousness, motivation, self-regulation, empathy, and mastery of relationships, which are five important elements of this type of intelligence.

\section{Kaynakça / References}

Arıcak O.T., Kınay H., ve Tanrıkulu T. (2012). Siber zorbalık ölçeğinin ilk psikometrik bulguları. Hasan Ali Yücel Ĕ̆itim Fakültesi Dergisi, 17(1), 101-114.

Arıcak, O.T. (2011). Siber zorbalık: Gençlerimizi bekleyen yeni tehlike. Kariyer Penceresi, 2(6), 10-12.

Arıcak, T. (2015). Siber alemin avatar çocukları. İstanbul: Remzi Kitabevi.

Ayas, T. ve Horzum, M. B. (2013). Rehber öğretmenlerin sanal zorbalık fakındalık düzeyinin çeşitli değişkenlere göre incelenmesi. Hacettepe Üniversitesi Ĕ̆itim Fakültesi Dergisi (H. U. Journal Of Education). 28(3), 195-205.

Aydın, H., (2017). Duygusal zeka (EQ) ve stres yönetimi ilişkisi. Yüksek lisans tezi, Nişantaşı Üniversitesi, İstanbul.

Binbaşıoğlu, C. (1990). Eğitim psikolojisi. (9.Basım). Ankara: Binbaşığlu Yayınevi.

Bollen, K.A. (1989). A new incremental fit index for general structural equation models. $\quad$ Sociological Methods and Research, 17(3), 303-316.

Browne, M. W. ve Cudeck, R. (1993). Alternative ways of assessing model fit. Sage Focus Editions, 154, 136-136.

Byrne, B. M. (2010). Structural equation modeling with AMOS: Basic concepts, applications, and programming (2nd ed.). New York: Taylor and Francis.

Campbell, M. A. (2005). Cyber bullying: An old problem in a new guise? Australian Journal Of Guidance And Counselling, 15, 68-76.

Cash, T. F. (2000). The multidimensional body-self relations questionnaire users' manual. Available from the author at www. body-images. com.

Çelik, Ş. (2008). Lise ëğrencilerinin öznel iyi oluşlarmın duygusal zeka açısından incelenmesi, (Yayımlanmamış Yüksek Lisans Tezi). Selçuk Üniversitesi, Konya.

Ciucci, E., ve Baroncelli, A. (2014). The emotional core of bullying: Further evidence of the role of callous-unemotional traits and empathy. Personality and Individual Differences, 67, 69-74. 
Costarelli, V., ve Stamou, D. (2009). Emotional intelligence, body image and disordered eating attitudes in combat sport athletes. Journal of Exercise Science \& Fitness, 7(2), 104-111.

Deniz, E. M., Özer, E., ve Işık, E. (2013). Duygusal zeka özelliği ölçeği-kısa formu: geçerlik ve güvenirlik çalışması (trait emotional intelligence questionnaireshort form:validity and reliability studies). Eğitim ve Bilim, 38(169).

Extremera, N., Quintana-Orts, C., Mérida-López, S., ve Rey, L. (2018). Cyberbullying victimization, self-esteem and suicidal ideation in adolescence: Does emotional intelligence play a buffering role?. Frontiers in psychology, 9: 367.

Gander, M. J., ve Gardiner, H. W. (1995). Çocuk ve ergen gelişimi (Bekir, O. Çev). Ankara: İmge.

Goleman, D. (2000). İş başında duygusal zeka. İstanbul: Varlık Yayınları.

Gürbüz, S., Yüksel, M., (2008). Çalışma ortamında duygusal zeka: iş performansı, iş tatmini, örgütsel vatandaşlık davranışı ve bazı demografik özelliklerle ilişkisi, Doğuş Üniversitesi Dergisi, 9(2), 174-190.

Hu, L. T. ve Bentler, P. M. (1999). Cutoff criteria for fit indexes in covariance structure analysis: Conventional criteria versus new alternatives. Structural Equation Modeling: A Multidisciplinary Journal, 6 (1), 1-55.

Karasar, N. (2015). Bilimsel araştırma yöntemi (28. Bas.). Ankara: Nobel Akdemi Yayıncllik.

Kavuk, M. (2011). İköğretim öğrencilerinin sanal zorba ve sanal kurban olma durumlarmmn incelenmesi. Yayınlanmamış Yüksek Lisans Tezi, Ankara Üniversitesi, Ankara.

Kline, R. B. (2011). Principles and practice of structural equation modeling. New York: The GuilfordPress.

Koç, M. (2004). Gelişim psikolojisi açısından ergenlik dönemi ve genel özellikleri. Sosyal Bilimler Enstitüsü Dergisi, 17, 231-256.

Kulaksızoğlu, A. (2000). Ergenlik psikolojisi (3. Baskı). İstanbul: Remzi.

Muth, J. L. ve Cash, T. F. (1997). Body-image attitudes: what difference does gender make? Journal of Applied Social Psychology, 27, 1438-1452.

Ögel, K. (2012). İnternet bağımlllı̆̆ı İstanbul: Türkiye İş Bankası Külttür Yayınları.

Ojedokun, O., ve Idemudia, E. S. (2014). Burnout among paramilitary personnel in Nigeria: A perspective from conservation of resources theory. South African journal of psychology, 44(1), 106-117.

Olweus, D. (1993). Bullying at school: What we know and what we can do understanding children's worlds, Oxford UK and Cambridge. USA: Blackwell Publishing Ltd. 
Petrides, K. V., ve Furnham, A. (2000). Gender differences in measured and self-estimated trait emotional intelligence. Sex roles, 42(5-6), 449-461.

Şanll, T. (1991). Hemşirelikte kişilerarası ilişkileri etkileyen temel kavramlar. (R. Geylan, Editör). Hemşirelikte kişilerarası ilişkiler içinde (s.49-83). Eskişehir: Anadolu Üniversitesi Yayınları.

Schumacker, R. E. ve Lomax, R. G. (2004). A beginner's guide to structural equation modelling. London: Lawrence Erlbaum Associates, Publishers.

Smolak, L. (2004). Body image development in children. In T. F. Cash and T. Pruzinsky, Çev.. Body image a handbook of theory, research and clinical practice. New York: The Guilford Pres.

Swami, V., Begum, S., ve Petrides, K. V. (2010). Associations between trait emotional intelligence, actual-ideal weight discrepancy, and positive body image. Personality and individual differences, 49(5), 485-489.

Tanaka, J. S. ve Huba, G. J. (1985). A fit index for covariance structure models under arbitrary GLS estimation. British Journal of Mathematical and Statistical Psychology, 38(2), 197-201.

Willard, N. (2007). Cyberbullying and Cyberthreats. U.S.A: Research Pres

Yavuzer, H. (2002). Egitim ve gelişim özellikleriyle okul çă̆ı çocuğu (8. Baskı). İstanbul: Remzi.

Yerli, S., (2009). İlk ve orta öğretim okullarnndaki yöneticilerin duygusal zeka ve problem çözme becerileri arasindaki ilişki "İstanbul Anadolu Yakası örneği. Yayınlanmamış yüksek lisans tezi, Maltepe Üniversitesi, İstanbul.

Yurdakavuştu, Y. (2012). İlköğretim öğrencilerinde duygusal zekâ ve sosyal beceri düzeyleri. Yayımlanmamış yüksek lisans tezi, Dokuz Eylül Üniversitesi, İzmir.

\section{Kaynakça Bilgisi / Citation Information}

Kırat, M. N. ve Dilmaç, B. (2021). Ergenlerde sanal zorbalık, beden imgesi ve duygusal zekâ arasındaki yordayıcı ilişkiler. OPUS-Uluslararası Toplum Araştırmaları Dergisi, 17(35), 1990-2007. DOI: 10.26466/opus.761037 